\title{
O CONCEITO DE SAÚDE NO LIVRO IV DA REPÚBLICA: PLATÃO CONTRA OS HIPOCRÁTICOS?
}

The concept of health in Republic book iv: Plato against the hippocratic?

El concepto de salud en la República: libro iv: Platón contra los hipocráticos?

Sussumo Matsui*

Gabriele Cornelli**

Resumo: O conceito de saúde trabalhado por Platão no Livro IV da República tem sido mal interpretado ao longo dos séculos. Para entender melhor quais seriam as colocações de Platão, é necessário entender e dialogar com o background da sua época. No caso do conceito de saúde é necessário um diálogo com a medicina hipocrática. Existe uma relação entre o conceito de justiça e saúde que não faz jus ao que está escrito. Platão, um hábil escultor de textos, faz um paralelo entre a alma e a cidade para descobrir o que é justiça e depois aplica ao indivíduo. Finda esta empresa, ele começa a delinear o que são atos de justiça. Tais atos são comparados com a saúde corporal. Isto é uma preparação para o discurso sobre os tipos de governo. Parece que o conceito de saúde não é o mesmo que encontramos desde Alcmeon até os hipocráticos, pois a temática da saúde se encontra em consonância com suas noções de política.

Palavras-chave: Saúde. Política. Justiça. Alma. Corpo. Hipocráticos.

\footnotetext{
* Mestre em Filosofia Antiga (Universidade de Brasília). Doutorando em Estudos Clássicos (Universidade de Coimbra).E-mail: flaviaesussumo@gmail.com

** Doutor em Filosofia pela Universidade de São Paulo (USP), e Doutor em Ciências da Religião pela Universidade Metodista de São Paulo (UMESP). Coordenador da Cátedra UNESCO Archai da Universidade de Brasília e Presidente da International Plato Society. Professor do Departamento de Filosofia da Universidade de Brasília (UnB). E-mail: gabriele.cornelli@gmail.com
} 


\begin{abstract}
The concept of health worked by Plato in Book IV of the Republic has been misunderstood for centuries. To better understand what are the statements of Plato, it is necessary to understand his background. In the case of health concept a dialogue with the Hippocratic medicine is needed. There is a relationship between the concept of justice and health unflattering to what is written. Plato, a skilled sculptor, texts draws a parallel between the soul and the city to find out what is justice and then applies to the individual soul. End this enterprise; it begins to outline what are acts of justice. Such acts are compared with bodily health. This is a preparation for the speech about the types of government. It seems that the concept of health is not the same, as we find from Alcmeon to the Hippocratic, because the health issue is in line with its policy notions.
\end{abstract}

Keywords: Health. Politics. Justice. Soul. Body. Hippocratic.

Resumen: El concepto de salud trabajado por Platón en el libro IV de la República ha sido mal entendido largo de los siglos. Para entender mejor lo que sería la colocación de Platón, es necesario entender y dialogar con el background de su tiempo. En el caso del concepto de salud es necesario un diálogo con la medicina hipocrática. Existe una relación entre el concepto de la justicia y salud que no coincide con lo que está escrito. Platón, un experto escultor textos, establece un paralelismo entre el alma y la ciudad para descubrir qué es la justicia y luego aplicar al individuo. Finda esta empresa, comienza a esbozar lo que son actos de justicia. Tales actos se comparan con la salud corporal. Esta es una preparación para el discurso sobre los tipos de gobierno. Parece que el concepto de salud no es el mismo que encontramos desde Alcmeón a los hipocráticos porque el tema de la salud está en línea con sus nociones de política.

Palavras-clave: Salud. Política. Justicia. Alma. Cuerpo. Hipocráticos. 


\section{Introdução}

A definição de saúde que encontramos na República de Platão foi submetida, ao longo do platonismo, a três leituras diferentes, que influenciaram decisivamente uma correta compreensão da questão. A primeira delas começou com Galeno ${ }^{1}$, na famosa afirmação que Platão foi um grande leitor de Hipócrates e seu maior imitador. A segunda teria sido a aceitação que Platão transpôs toda a teoria de Alcmeon de Crotona para suas teses biológicas. Por fim, a terceira leitura deu um salto, quase inconscientemente, do conceito de justiça ${ }^{2}$ ao de saúde, relacionando-os em um sentido de isomorfia e causalidade.

O presente artigo propõe superar a recepção platonista da questão da saúde para voltar ao texto platônico e aos escritos hipocráticos, comparando o texto da República com as definições que encontramos nos escritos médicos datados mais ou menos da mesma época. ${ }^{3}$ Seguimos uma hipótese pela qual os conceitos platônicos parecem representar uma polêmica contra a medicina de seu tempo. Porém, devemos ter cuidado para não cair no erro dos positivistas ${ }^{4}$, crendo que Platão polemizava contra Hipócrates ou contra uma determinada corrente (itálica ou de Cnido).

Depois de uma digressão no interior da discussão sobre a educação dos guardiões, no Livro III, Platão denuncia que a medicina de seu tempo estava em declínio ( $R$. 406a). Ele critica o excessivo cuidado da saúde, que tinha se transformado em cuidado da doença ( $R$. 407b-c). O contexto deste artigo se desenvolve no Livro IV, na tripartição da alma. Nessa

\section{PHP 4.}

2 Existe um grande debate em torno da justiça em Platão. Não iremos enfrentar este problema, pois a definição textual é suficiente para demonstrar o analogon entre justiça e saúde. Para o debate sobre a justiça, ver Irwin (1977, p. 204-216); Keyt (2011, p. 318 32); Kraut (2013, p. 367-97); Vlastos (1968, p. 665-674). Deve-se ter em mente que o conceito de justiça é mais amplo do que o que foi exposto no Livro IV. Segundo Richard Kraut, ele se desenvolve nos demais livros da República.

3 Existe muita dúvida na datação, pois este é um trabalho espinhoso e cheio de especulações. Ao falar de uma datação comum entre a República e os tratados hipocráticos, temos em mente algo mais geral, ou seja, as obras que circulavam na última metade do século $\mathrm{V}$ e na primeira metade do século IV a.C.

4 Houve uma discussão sobre a existência de três escolas de medicina rivais na Antiguidade: Cós, Cnido e Itália. Jaeger (2001, p. 1.030-1.031) afirmou que Platão seguia a escola de Cós. Disto decorre que ele estava polemizando contra a escola empírica de Cnido. 
passagem, Platão faz duas analogias que estão relacionadas diretamente com o conceito de saúde: o analogon entre justiça e a tripartição da alma e o analogon entre ações justas e saúde. É necessário investigá-los com cautela para saber se Platão está polemizando com os hipocráticos no campo conceitual.

\section{O analogon entre justiça e alma tripartida}

Ao voltar para o tema da educação dos guardiões, Adimanto indaga a Sócrates o motivo pelo qual os guardiões, que detêm o governo da cidade, não poderem possuir alguma propriedade. Ele pergunta se esse grupo de pessoas não será infeliz. Sócrates responde que o objetivo não é tornar uma só classe muito feliz, mas garantir a felicidade da cidade inteira (419a-421c). Nesta cidade bela (kallipolis) não se deve permitir nem a pobreza nem a riqueza extrema. Pois a primeira engendra o servilismo, a ineficiência e o gosto pela novidade; a segunda engendra o luxo, a preguiça e o gosto pela novidade. É fundamental que haja uma educação pormenorizada (421d-427c).

Estes governantes detêm um "saber governar" (428d) que consiste em uma capacidade prático-política de tomar decisões justas com vistas à vantagem da cidade inteira. A qualidade típica deles é a sabedoria (sophia, 429a). A segunda classe de pessoas, a dos guardiões, deve ser dotada de coragem (andreia). Uma coragem não é só uma virtude a ser exercida nos campos de batalha, mas é uma fidelidade aos princípios morais estabelecidos pela lei e uma educação apropriada sobre o que deveriam temer (429b-430c). A terceira qualidade (430d-432a), a temperança (sophrosyne), deve estar presente em todos os grupos sociais de forma distributiva. A temperança presente na classe dos governantes e guardiões faz com que estes não se transformem em opressores dos súditos. Já no terceiro grupo, a temperança põe limites nos prazeres, no acúmulo de riquezas, no desejo de poder. Por fim, a justiça (dikaiosyne) garante que as outras três virtudes (sophia, andreia, consiste (434a):

a) em reter apenas os bens que nos são próprios. Como já notava Vlastos (1968, p. 667), esta primeira metade do conceito de justiça parece polemizar com o estado de pleonexia descrito por Tucídides (5. 105); 
b) em exercer a nossa própria função, isto é, respeitar os próprios limites e o próprio papel (oikeiopragia 434c). Na gênese da cidade, Sócrates explica a Glauco que a multiplicidade das necessidades reúne em um mesmo local um grande número de associados e auxiliares $(369 \mathrm{e}-$ $370 \mathrm{a}$ ), e cada um deve cumprir a sua própria função (autou prattein).

Para que a justiça seja plena, Platão não permite a troca de funções e nem a prática de várias atividades (434b-c). É bem provável que ele esteja criticando a pressuposta liberdade democrática, que os atenienses tanto se orgulhavam, a qual permitia aos cidadãos uma versatilidade na prática e exercício de várias formas de atividades. ${ }^{5} \mathrm{Na}$ kallipolis, cada um deveria fazer sua função.

A tripartição funcional do corpo social foi introduzida para superar a cisão econômica entre ricos e pobres, que condenaria a cidade a um conflito perpétuo. Então, a função da justiça seria garantir a felicidade coletiva na oikeiopragia política dos três grupos. Agora nos resta transferir este modelo para a dimensão individual, segundo o método proposto no início, para investigar se existe algum isomorfismo entre as duas justiças (coletiva e individual).

No indivíduo existe um conflito. Platão constata que a alma se divide em três partes: ${ }^{6}$ racional (logistikon), desiderativa (epithymias) e irascível (thymoeidous). A divisão é análoga aos grupos da cidade, pois cabe à parte racional, comandar; à irascível, vigiar; e a desiderativa, desejar (434c-441c). Esta última necessita de freio e direção.

Poderíamos representar assim o analogon:

\begin{tabular}{|c|c|c|c|}
\hline CIDADE & $\begin{array}{c}\text { Governantes } \\
\text { (sophia) }\end{array}$ & $\begin{array}{c}\text { Guardiões } \\
\text { (andreia) }\end{array}$ & $\begin{array}{c}\text { Artesãos } \\
\text { (sophrosyne) }\end{array}$ \\
\hline ALMA & $\begin{array}{c}\text { Racional } \\
\text { (logistikon) }\end{array}$ & $\begin{array}{c}\text { Irascível } \\
\text { (thymoeidous) }\end{array}$ & $\begin{array}{c}\text { Desiderativa } \\
\text { (epithymias) }\end{array}$ \\
\hline
\end{tabular}

Cf. Thuc. 2. 41.

6 A tripartição da alma é discutida em Robinson (2007, p. 78-85), Santos (2009, p. 71-80), Miller (2011, p. 261-275). 
Se há uma isomorfia entre os três elementos então, o conceito de justiça que foi aplicado à cidade também pode ser aplicado ao indivíduo. Contudo, Vegetti (2011, p. 61-62) assinala que muita dificuldade hermenêutica vem da aceitação que a forma política, em termos de força e poder, é completamente isomórfica ao conflito intrapsíquico. Platão mesmo reconhece as dificuldades, dizendo que com os métodos utilizados na discussão, não o levará jamais a atingir rigorosamente o fim proposto (435c-d). Ele continua dizendo que o método bastava para a presente circunstância e que haveria um caminho mais longo e demorado.

\section{O analogon entre ações justas e a saúde}

Estabelecido o conceito de justiça, Sócrates pergunta sobre o conceito de atos de justiça. Aqui reside uma grande confusão quando se lê a passagem. Como foi mostrado acima, a justiça na alma é semelhante à justiça na cidade. Até agora a saúde não foi evocada. A partir da passagem 444c, Sócrates constrói outro analogon entre ações justas e saúde do corpo:

- Ora, produzir a saúde consiste em dispor, de acordo com a natureza, os elementos do corpo para dominarem ou serem dominados uns pelos outros; a doença, em, contra a natureza, governar ou ser governado um por outro.

- Consiste, sim.

- Portanto, inversamente - produzir a justiça consiste em dispor, de acordo com a natureza, os elementos da alma, para dominarem ou serem dominados uns pelos outros; a injustiça, em contra a natureza, governar ou ser governado um pelo outro $(R .444 \mathrm{~d}){ }^{7}$

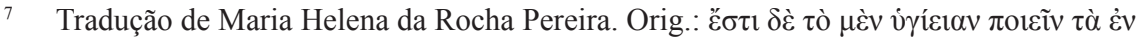

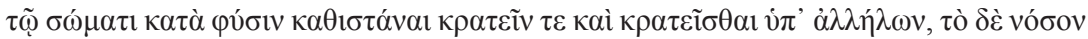

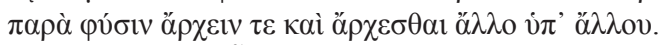

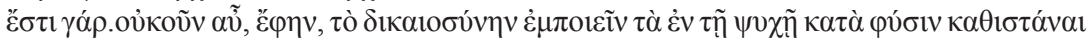

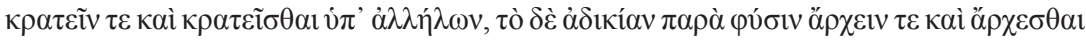

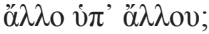


O analogon pode ser representado da seguinte forma:

\begin{tabular}{|c|c|c|}
\hline Alma & Ações justas & $\begin{array}{c}\text { Elementos dominando } \\
\text { segundo a natureza }\end{array}$ \\
\hline Corpo & Saúde & $\begin{array}{c}\text { Elementos dominando } \\
\text { segundo a natureza }\end{array}$ \\
\hline Alma & Ações injustas & $\begin{array}{c}\text { Elementos governando } \\
\text { contra a natureza }\end{array}$ \\
\hline Corpo & Doença & $\begin{array}{c}\text { Elementos governando } \\
\text { contra a natureza }\end{array}$ \\
\hline
\end{tabular}

O conceito de saúde que Platão delineia é a dominação ( krateisthai $^{8}$ ) de um elemento sobre outro de acordo com a natureza, assim como o elemento racional domina os outros elementos na alma. Ele encerra o Livro IV dizendo que as constituições políticas são tantas quantas as espécies de alma. Mas a melhor delas é a monarquia ou a aristocracia.

Platão não se aproxima de um conceito "democrático" de saúde. Não é uma isonomia dos elementos que está em jogo, mas o domínio de um sobre os outros. O vocábulo "harmonia" não é evocado no analogon acima. Mas muitos filósofos e historiadores da filosofia fizeram uma ligação entre Platão e a medicina grega através da noção de harmonia. Giovani Reale (2002, p. 188) afirma com segurança que o conceito de saúde em Platão "é a justa proporção, a harmonia natural, o acordo intrínseco do organismo consigo mesmo e com o que lhe é exterior." Gadamer (2011, p. 105) diz que a saúde era vista como harmonia pelos gregos e, principalmente, por Platão. $\mathrm{O}$ conceito de harmonia pode ser comum à medicina grega e Platão, mas eles se divergiam sobre como se processa esta harmonia.

Alcmeon é sem dúvida parte de uma tradição de filosofia da saúde. ${ }^{9}$

8 Platão está usando o verbo krateo para a saúde e archo para a doença. De acordo com Chantraine (1968, p. 119-121; 578-579), é difícil precisar a etimologia da palavra archo, pode ser que ela esteja ligada com a ideia de começar, tomar iniciativa. Depois de Homero, o verbo toma o sentido de comandar. Segundo LSJ, a maioria dos vocábulos administrativos recebe a raiz arch. Já o verbo krateo tem o sentido de força física que permite triunfar, vitória, poder, soberania, controle.

9 Existe uma questão sobre a relação entre Alcmeon e os pitagóricos. Não é nosso objetivo entrar neste debate, para maiores detalhes ver Cornelli (2009, p. 41). Para as teorias cosmológicas de Alcmeon ver Burnet (1994, p. 159 - 161), Casertano (2011, p. 58-59, 76-77), Kirk, Raven, Schofield (1994, p. 365). Para uma análise detalhada da medicina em Alcmeon ver Cornelli (2009, p. 40-42), Jouanna (1992, p. 459-461), Vegetti (1965, p. 91-94), Longrigg (1988, p. 47-81). 
Ele é reconhecido como uma figura de grande importância no desenvolvimento das ciências biológicas na Grécia antiga. Alguns, ${ }^{10}$ inspirados no "milagre grego", ${ }^{11}$ enalteceram a figura de Alcmeon, a ponto de dizer que ele era o pai da anatomia, da fisiologia, da embriologia, da psicologia e da própria medicina. Evitando cair em exagero, pode-se hoje (VEGETTI, 1965, p. 94) atribuir a Alcmeon a distinção entre a inteligência e a sensação. Poder-se-á também atribuir a ele a teoria que coloca o cérebro como intérprete da sensação e órgão da inteligência, bem como o primeiro experimento de dissecção. ${ }^{12}$

Para Alcmeon (DK 24 B4), a saúde (hygieias) é a isonomia (isonomian) das forças (ton dynameon) opostas: úmido-seco, frio-quente, amargo-doce etc. Existindo a monarquia ou a senhoria (monarchian) de um deles, produz-se a doença (nosou). A saúde (hygieian) é a mistura (krasin) simétrica (symmetron) das qualidades. A isonomia torna-se o coração da ética antiga, e "especialmente, em sentido político e jurídico: a ideia acaba permeando toda a cultura" (CORNELLI, 2009, p. 40-41). A saúde para Alcmeon era "o estabelecimento de um governo livre e com leis igualitárias" (BURNET, 1994, p. 161). Segundo Vegetti (1965, p. 94), a ideia de isonomia e krasis orientaram também o pensamento hipocrático, principalmente dos tratados Da medicina antiga e Dos ares, águas e lugares. Também se notam claros traços da etiologia alcmeonica nos tratados Da dieta nas doenças agudas e Epidemias.

As duas principais definições de saúde se encontram em dois tratados que, coincidentemente, rejeitam a influência da filosofia e afirmam a independência da medicina (JOUANNA, 1992, p. 456-459). A primeira obra é o tratado Da medicina antiga. O autor hipocrático (VM 14) define a saúde pelo oposto, ou seja, a doença. Ele afirma que quando os elementos presentes no homem (tais como salgado, amargo, doce) são mesclados (memigmena) e bem misturados $\left(\right.$ kekremena $\left.^{13}\right)$ uns com os outros, eles não trazem sofrimen-

10 Burnet (1994, p. 159-61) afirma que Alcmeon foi o pai da psicologia empírica, e que Hipócrates e Platão dependem dele para descrever o cérebro como o sensório comum.

11 Lloyd (1991, p. 167, n 2) elenca uma vasta bibliografia sobre o assunto.

12 Segundo Lloyd (1991, p. 178), Alcmeon não estava interessado em um método de dissecção em si, mas em problemas teóricos tal como o da sensação.

13 Jouanna (1990) e Festugière (1979) traduzem kekremena por "temprerées". Vegetti (1965) traduz por "contemperate. Schiefsky (2005) traduz por "blended". Garcia Gual (1993) traduz por combinados. O texto de Jones traz "compounded". A ideia é similar ao 
to, ${ }^{14}$ mas se um deles se separa (apokrithe) e subsiste por si mesmo, então nasce o estado doentio. Schiefsky (2005, p. 248-254) explica que no texto a ideia de mistura dos componentes é feita de forma que o caráter individual de cada um não se manifeste até que sejam separados uns dos outros e se tornem concentrados.

Outra obra é o tratado Da natureza do homem. O autor (Nat.Hom. 4) define a saúde como o estado de perfeita mistura (kresios), e de proporção dos poderes ${ }^{15}$ (dynamios) e quantidades (pletheos), dos quatro elementos: sangue (aima), flegma ( phlegma), bile amarela e bile negra (cholen xanthente kai melainan). A doença, por sua vez, surge quando um dos elementos se separa em maior ou menor quantidade no corpo, e não se mescla com todos os demais. Apesar das diferenças entre os tratados Da medicina antiga e Da natureza do homem, as duas definições apresentam pontos comuns:

a) a saúde e a doença são estados radicalmente opostos;

b) a saúde é definida pela mistura de todos os elementos do corpo e

c) a doença é definida pela separação e isolamento de um elemento em relação aos outros.

Por fim, existe uma definição de saúde em um tratado eclético de inspiração filosófica, o Regime. O autor hipocrático (Vict. 69) define a saúde como a igualdade (isazein) dos fatores e a doença como a predominância $\left(\right.$ krateisthai $^{16}$ ) de um fator sobre o outro. Apesar de uma semelhança com o vocabulário da República, o autor fala em um contexto diferente. Aqui os fatores que ele se refere são alimentos e exercícios. Na República, Platão é mais amplo, pois ele não fala de fatores, elementos ou humores.

cozimento dos alimentos: é uma boa mistura (Liddell-Scott), quase que podemos dizer "homogênea".

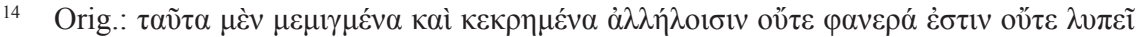

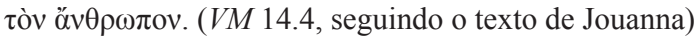

15 Schiefsky (2005, p. 247) segue Jouanna traduzindo dynamis por poderes. O autor hipocrático considera dynamis como uma capacidade de causar um tipo específico de efeito, que também possui uma certa força ou intensidade.

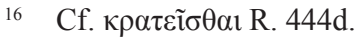




\section{Conclusão}

O conceito platônico de saúde não parece estar polemizando com uma específica obra hipocrática. Todavia, a discussão acima, nos permite concluir que há sim uma intenção polêmica implícita com a tradição médica, a mesma que teve início com Alcmeon. Se não contra o próprio Alcmeon, Platão está certamente discutindo os desdobramentos do conceito de saúde que essa tradição carrega consigo. Tal desdobramento resulta numa noção de saúde permeada por uma "democracia" dos elementos; a saúde é resultado de uma boa mescla dos humores. Uma perfeita homogeneidade dos elementos é o objetivo desta intervenção médica, por assim dizer.

A crítica à medicina do Livro III somada a este conceito de saúde resulta que Platão segue em rota de colisão com o conceito hipocrático de saúde-doença ${ }^{17}$. Este conceito de saúde é fundamental para entendermos como o debate entre saúde e política estava interligado na Antiguidade. Platão, ao recusar o modelo "democrático, sugere que a saúde deva ser a relação de dominação e sujeição entre os elementos do corpo segundo a natureza (444d). Assim também, a boa constituição só pode ser monárquica ou aristocrática (445d).

Seguindo este fio condutor, parece que Platão não está utilizando a medicina hipocrática como um modelo para sua teoria ética ou política, mas afastando-se radicalmente desta. O conceito de saúde platônico é, assim, uma tentativa de afastar os traços políticos da democracia dos postulados da "fisiologia" hipocrática.

\section{Referências}

\section{a) Fontes antigas}

GALENO. On the doctrines of Hippocrates and Plato. Edição, tradução e comentário de Phillip de Lacy. 3 ed. Berlin: Akademie Verlag, 2005.

HIPÓCRATES. Tratados Hipocráticos. Edição de Garcia Gual. Madri: Editorial Gredos, 1993-2008, 8 v.

17 Esta opinião é defendida também por Ayache (1992, p. 120); Levin (2014, p. 16) 
HIPÓCRATES. On ancient medicine. Tradução, introdução e comentário por M. J. Schiefsky. Boston: Brill, 2005.

. Opere di Ippocrate. Tradução e introdução por Mario Vegetti. Torino: Tipografico Editrice Torinese, 1965.

. L'ancienne médecine. Introdução e comentário por A.-J Festugière. Nova Iorque: Arno Press, 1979.

PLATÃO. A república. Introdução, tradução e notas de Maria Helena da Rocha Pereira. 9 ed. Lisboa: Fundação Calouste Gulbenkian. 2001.

TUCÍDIDES. História da guerra do Peloponeso. Brasília: Editora UnB, 2001.

\section{b) Fontes modernas}

AYACHE, L. Hippocrate. Paris: Presses Universitarires de France, 1992.

BURNET, J. O despertar da filosofia grega. São Paulo: Siciliano, 1994.

CORNELLI, G. Calcular a saúde: a saúde como equilíbrio de forças na tradição pitagórica. In.: PEIXOTO, M. C. D. A saúde dos antigos: reflexões gregas e romanas. São Paulo: Edições Loyola, 2009, p. 33-42.

GADAMER, H-G. O caráter oculto da saúde. São Paulo: Editora Vozes, 2011.

IRWIN, T. Plato's moral theory: the early and middle dialogues. Oxford: Oxford University Press, 1977.

JAEGER, W. Paidéia: a formação do homem grego. São Paulo: Martins Fontes, 2001.

JOUANNA, J. Hippocrate. Paris: Fayard, 1992.

KEYT, D. Platão e a justiça. In: BENSON, H. (Org.). Platão. Porto Alegre: Artmed, 2011, p. 318-332.

KIRK, G. S.; RAVEN, J. E.; SCHOFIELD, M. Os filósofos pré-socráticos. Lisboa: Fundação Calouste Gulbenkian, 1994. 
KRAUT, R. A defesa da justiça na República de Platão. In: . (Org.). Platão. São Paulo: Ideias e Letras, 2013, p. 367-397.

LEVIN, S. Plato's rivalry with medicine: a struggle and it's dissolution. Oxford: Oxford University Press, 2014. http://dx.doi.org/10.1093/acprof:oso/9780199919802.001.0001

LLOYD, G. E. R. Methods and problems in Greek science. Cambridge: Cambridge University Press, 1991.

LONGRIGG, J. Greek rational medicine: philosophy and medicine from Alcmeaon to the Alexandrians. London: Routledge, 1993. http://dx.doi. org/10.4324/9780203328354

MILlER, F. D. A alma platônica. In: BENSON, H. (Org.). Platão. Porto Alegre: Artmed, 2011, p. 261-275.

REALE, G. Corpo, alma e saúde: o conceito de homem de Homero a Platão. São Paulo: Paulus, 2002.

ROBINSON, T. M. A psicologia de Platão. São Paulo: Edições Loyola, 2007.

SANTOS, J. G. T. Para ler Platão: alma, cidade, cosmo. São Paulo: Edições Loyola, 2009.

VEGETTI, M. Guida alla lettura della Repubblica di Platone. 5 ed. Bari: Editora Laterza, 2011.

. La medicina in Platone. Venezia: Il Cardo, 1995.

VLASTOS, G. The argument in the Republic that "justice pays". In: . The Journal of Philosophy, Canada, v. 65, n. 21, p. 665-674, Nov.

1968. http://dx.doi.org/10.2307/2024542

Data de registro: $22 / 07 / 2015$

Data de aceite: 20/04/2016 